\title{
RANCANG BANGUN SISTEM MONITORING DAN KONTROLING PARKIR BERTINGKAT OTOMATIS BERBASIS ARDUINO DENGAN IMPLEMENTASI INTERNET OF THINK(IOT)
}

\author{
Yengki Maskurdianto \\ Program Studi Teknik Informatika S1, Fakultas Teknologi Industri \\ Institut Teknologi Nasional Malang, Jalan Raya Karanglo km 2 Malang, Indonesia \\ Yengkimaskur@gmail.com
}

\begin{abstract}
ABSTRAK
Parkir adalah berhenti dan ditinggalkannya kendaraan oleh pengendara untuk sementara waktu pada suatu ruang tertentu. Belakangan ini kebutuhan masyarakat terhadap tempat parkir semakin meningkat, hal ini disebabkan oleh semakin banyaknya masyarakat yang menggunakan mobil pribadi untuk menjalankan aktivitasnya, tidak terkecuali ketika pergi ke tempat-tempat umum dan juga gedung bertingkat. Terbatasnya informasi tentang ketersediaan lahan parkir menyebabkan pengunjung kesulitan untuk menentukan lokasi parkir kendaraan mereka.

Pesatnya kemajuan ilmu pengetahuan dan teknologi komunikasi saat ini khususnya pada bidang internet of things sangat membantu meringankan pekerjaan manusia dalam berbagai hal. Pada system ini dibuat sistem monitoring dan kontroling parkir otomatis pada gedung bertingkat. Sistem dapat mengetahui mendeteksi kendaraan pada tiap lantai yang selanjutnya data dikirim ke database dan ditampilkan pada website.

Sistem Monitoring dan Kontroling parkir bertingkat berbasis arduino ini diharapkan dapat membantu kinerja para petugas tempat parkir dalam memonitor tempat parkir. Sistem ini juga berguna bagi pengunjung dan calon pengunjung untuk menentukan lokasi untuk parkir kendaraan pribadi milik mereka. Dengan system ini, pekerjaan menentukan lokasi parkir yang masih kosong dilakukan secara otomatis dengan menghitung jumlah kendaraan pada tiap lantai dan mengurangkan dengan kapasitas parkir perlantai dengan menggunakan sensor ultrasonik yang nantinya akan diproses oleh arduino uno dan data akan dikimkan dengan modul esp8266. Sistem ini juga dapat membatu pengelola dalam mengelola pendapatan parkir.
\end{abstract}

Kata kunci : Parkir gedung bertingkat, Arduino uno, Ultrasonik, Monitoring.

\section{PENDAHULUAN}

Salah satu faktor penarik pelanggan pada Kawasan pusat perbelanjaan ataupun pada bidang Kawasan perkantoran adalah kemudahan untuk memarkirkan kendaraan mereka. Misalkan luasnya lahan parkir, kenyamanan pelayanan parkir atau kemudahan dalam mendapatkan tempat parkir dalam kondisi padat pengunjung. Banyak para pengguna parkir pada kesulitan dalam mencari slot parkir dikarenakan banyaknya pengguna parkir, tidak terkecuali parkir pada gedung bertingkat. Sistem parkir pada gedung bertingkat saat ini masih menggunakan banyak operator sebagai pengatur ataupun pencari slot pada tiap lantai dan akan bertukar informasi melalui alat komunikasi berupa radio. Tidak jarang pengendara harus menyusuri tiap area dan tiap lantai pada area parkir gedung bertingkat untuk mendapatkan area yang masih kosong dengan memakan waktu. Dalam hal ini petugas juga harus berkeliling area parkir untuk memastikan semua kendaraan aman dan terkendali. Pengguna parkir juga tidak dapat memantau kendaraannya secara langsung jika terjadi suatu hal yang tidak diinginkan.

Pemanfaatan teknologi saat ini sudah banyak yang mendukung monitoring sebuah objek via internet. Teknologi yang bisa mengidentifikasi, menemukan, memantau objek dan memicu kejadian secara otomatis dan realtime. Seperti penelitian yang pernah dilakukan oleh Irawan, 2016, dengan judul pengembangan Perkembangan Kunci Elektronik Menggunakan RFID dengan Sistem IOT.adapun hasil penelitiannya adalah teknologi internet khususnya Internet of Things (IoT) belakangan ini semakin pesat. Internet of Things adalah layanan yang memunkinkan untuk menghubungkan objek (things) baik fisik maupun virtual melalui jaringan internet. Berdasarkan permasalahan yang telah dikemukakan maka akan dibangun sebuah sistem yang dapat memonitoring dan menggontrol parkir secara otomatis dengan implementasi internet of things. Pada sistem tersebut untuk mendeteksi keberadaan kendaraan yang lewat dibutuhkan sensor ultrasonik yang berfungsi 
mendeteksi jarak yang dimanfaatkan untuk mendeteksi jika terdapat kendaraan yang lewat. Untuk memantau keadaan kendaraan pada area parkir dibutuhkan ip kamera yang dapat merekam kejadian realtime dan dapat dipantau memalui internet. Untuk memberikan informasi kepada pengelola dan pengguna parkir pada gedung bertingkat data jumlah kendaraan yang telah diproses akan dikirim melalui internet dan disimpan kedalam database yang nantinya akan ditampilkan pada website monitoring.

\section{TINJAUAN PUSTAKA}

\subsection{Penelitian Terdahulu}

Internet of Things (IoT) adalah era baru dalam bidang internet, IoT dapat digambarkan alat-alat elektronik yang dapat digunakan seharihari yang saling dihubungkan kedalam jaringan komputer sebagai sarana meningkatkan kegunaan internet dengan cara menghubungkan peralatan elektronik agar dapat berinteraksi melalui sistem embedded, yang akan membentuk hubungan komunikasi antar peralatan elektronik[1]. Kemunculan teknologi ini didorong oleh semakin banyaknya perangkat yang terhubung melalui internet dan kemampuan dari tiap-tiap perangkat untuk saling berkomunikasi tanpa adanya campur tangan manusia. Beberapa istilah lain yang memiliki korelasi terhadap IoT adalah Web of Things, Machine-to-Machine Communication atau Internet of Everything[2].

IoT itu sendiri tersusun dari tiga bagian utama yaitu objek (things), konektivitas jaringan (network) dan layanan internet (cloud). Ditinjau dari bagian-bagian yang ada di dalamnya, objek atau things dari IoT membutuhkan disiplin ilmu elektro, seperti instrumentasi sensor, mikropengendali, manajemen daya, pengolahan sinyal, komponen-komponen elektronika dan semikonduktor. Sedangkan untuk membuat agar ketiga bagian tersebut dapat saling terhubung, diperlukan tenaga-tenaga yang menguasai keterampilan jaringan komputer. Kemampuan pemrograman untuk mengakses berbagai layanan internet juga merupakan satu nilai tambah yang penting[3].

\subsection{Internet of things}

Internet of things adalah sebuah teknologi yang memungkinkan kita untuk menghubungkan mesin, peralatan, dan benda fisik lainya dengan sensor jaringan dan aktuator untuk memperoleh data dan mengelola kinerjanya sendiri, sehingga memungkinkan mesin untuk berkolaborasi dan bahkan bertindak berdasarkan informasi baru yang diperoleh secara independen[4]

\subsection{Embeded system}

Embedded System adalah kombinasi antara harchvare dan software computer, atau mungkin dengan tambahan organel mekanik atau elektronik, yang didesain untuk fungsi tertentu [5]. Embedded System berbeda dengan computerpada umumnya. Embedded System memilikiukuran yang lebih kecil daripada komputer biasa.Hal ini dikarenakan embedded system sudahmemiliki tujuan dan fungsi yang spesifik, sehingga perangkat elektronik yang ditanamkanpada embedded system tidak perlu terlalu banyak, berbeda dengan komputer yang pada umumnya memerlukan semua perangkat untuk input, proses, output, penyimpanan, dan komunikasi. Hal ini membuat embedded system menjadi sebuah teknologi yang unik dan sangat diminati oleh manusia pada zaman ini.

\subsection{Arduino Uno}

Arduino Uno adalah board mikrokontroler yang di dalamnya terdapat mikrokontroler, penggunaan jenis mikrokontroler-nya berbeda beda tergantung spesifikasinya. Pada Arduino Uno diguanakan mikrokontroler berbasis ATmega 328. Memiliki 14 pin input dari output digital dimana 6 pin input tersebut dapat digunakan sebagai output PWM dan 6 pin input analog, $16 \mathrm{MHz}$ osilator kristal, koneksi USB, jack power, ICSP header, dan tombol reset. Adapun data teknis board Arduino UNO dan gambar adalah sebagai berikut:

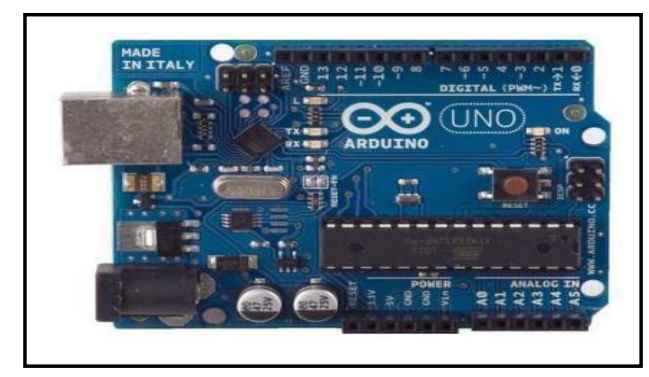

Gambar 2.1 Arduino Uno

\subsection{Sensor Ultrasonik}

Sensor Jarak Ultrasonik merupakan sensor yang digunakan untuk mengukur jarak sebuah benda dengan memanfaatkan sinyal suara ultrasonik. Sensor ini menghasilkan gelombang suara pada frekuensi tinggi yang kemudian dipancarkan oleh bagian emitter [6]. Pantulan gelombang suara (echo) yang mengenai benda di depannya akan ditangkap oleh bagian receiver. Jarak benda yang ada di depan modul sensor tersebut didapatkan dengan cara mengetahui lama waktu antara dipancarkannya gelombang suara oleh emitter sampai ditangkap kembali oleh 
receiver. Salah satu jenis sensor ini adalah sensor HC-SR04. Jarak pengukuran yang dapat dilakukan oleh sensor ini adalah 2 sampai 500 sentimeter, dengan sudut efektif sebesar kurang dari 15 derajat. Gambar sensor jarak HC-SR 04 ditunjukkan pada gambar berikut [2.2].

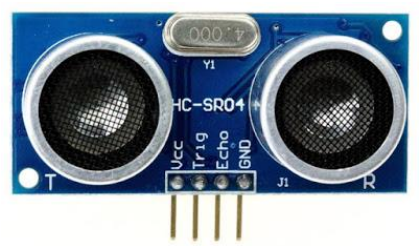

Gambar 2.2 Sensor Ultrasonik

\subsection{Modul Wifi ESP8266}

ESP8266 adalah chip terintegrasi yang di rancang untuk kebutuhan terhubungnya dunia. Ia menawarkan solusi jaringan wifi yang lengkap dan mandiri, yang memungkinkan untuk menjadi host atau mentranfer semua fungsi jaringan wifi dan prosesor aplikasi lain[7]. ESP8266 memiliki kemampuan pengolahan dan penyimpanan onboard yang kuat, yang memungkinkan untuk diintegrasikan dengan sensor dan aplikasi perangkat khusus lain melalui GPIOs dengan pengembangan yang mudah loading waktu yang minimal [8].

ESP8266 yang berkolaborasi dengan Arduino uno digunakan untuk mengirim data suhu dari hasil pembacaan sensor Ultrasonik. Data akan dikirim ke server. ESP8266 menggunakan ATcommand sebagai perintahperintah dasarnya.

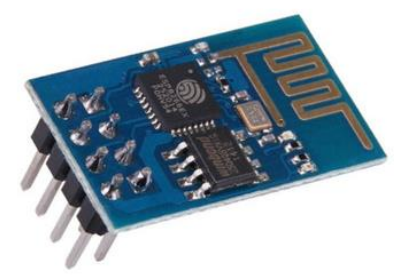

\section{Gambar 2.3 Modul Wifi ESP8266}

\subsection{Motor Servo}

Motor servo adalah sebuah motor DC dengan sistem umpan balik tertutup di mana posisi rotor-nya akan diinformasikan kembali ke rangkaian kontrol yang ada di dalam motor servo. Motor ini terdiri dari sebuah motor DC, serangkaian gear, potensiometer, dan rangkaian kontrol. Potensiometer berfungsi untuk menentukan batas sudut dari putaran servo. Sedangkan sudut dari sumbu motor servo diatur berdasarkan lebar pulsa yang dikirim melalui kaki sinyal dari kabel motor servo. Motor servo ini berfungsi sebagai motor penggerak untuk membuka dan menutup palang pintu parkir.

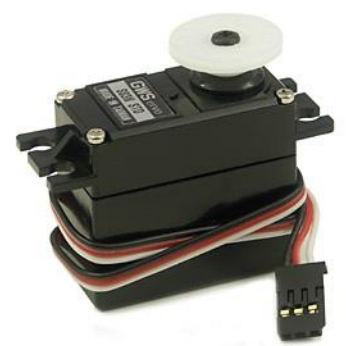

Gambar 2.4 motor servo

\section{METODE PENELITIAN}

Penelitian pada rancang bangun sistem monitoring dan kontroling parkir bertingkat ini akan mempermudah penguna maupun pengelola. Sistem ini dapat mempermudah pengguna dalam mencari slot parkir pada gedung bertingkat tanpa harus mengecek semua lokasi parkir.

\subsection{Blok diagram}

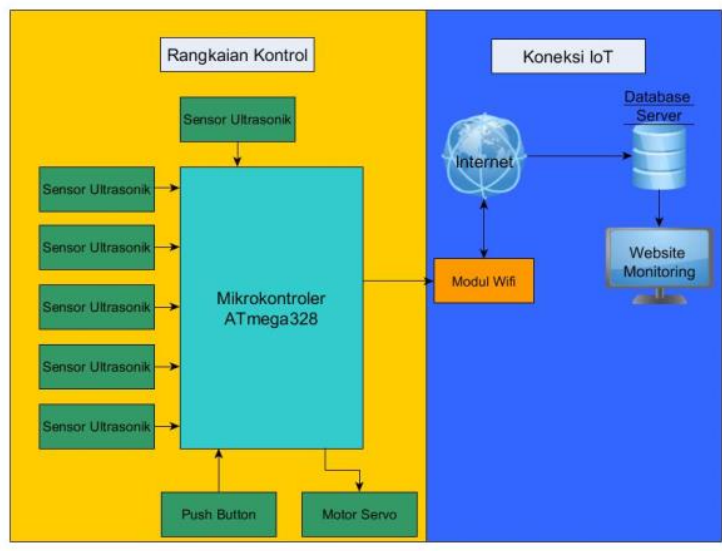

Gambar 3.1 Blok diagram system.

\subsection{Flowchart Sistem Hardware}

Flowchart sistem hardware menggambarkan alur kerja dari hardware dan sitem monitoring untuk mengatahui slot pada parkir bertingkat. Pada gambar 3.1. menjelaskan alur kerja hardware yang dimulai dari inisialisasi sensor yang digunakan. Terdapat dua tombol untuk membuka dan menutup palang pintu dan 6 sensor untrasonik yang dibaca secarabergantian. 


\subsection{Flowchart sistem website}

Pada Gambar 3.2 menggambarkan alur kerja dari system. Terdapat beberapa fitur untuk menampilkan keadaan tempat parkir realtime yaitu jumlah kendaraan yang terdapat pada lantai 1 sampai 8 , cetv per lantai dan juga monitoring grafik dan logger.

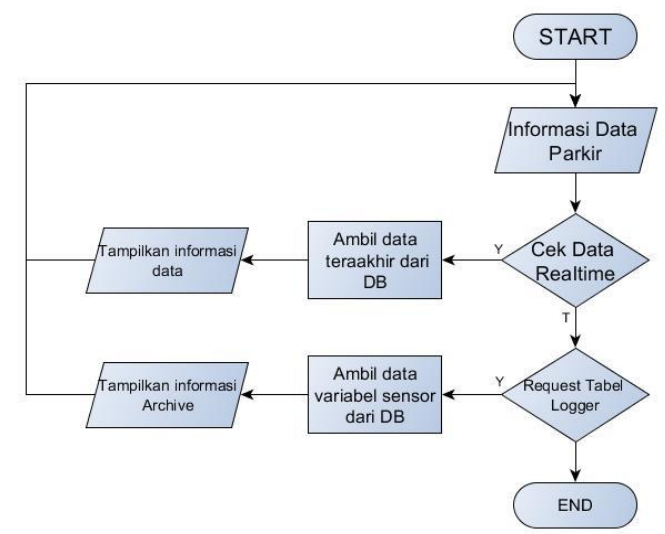

Gambar 3.3 Flowchart Sistem Software

\subsection{Skema Rangkaian Alat}

Skema rangkaian alat merupakan gambaran dari model alat yang akan dibuat. Skema rangkaian alat monitoring dan kontroling parkir bertingkat terdiri dari Arduino uno R3 sebagai pusat kendali, sensor ultrasonik untuk mengukur jarak yang berfungsi untuk mendeteksi mobil yang lewat, tomboll sebagai kontrol buka tutup servo, dan modul wifi esp8266 berfungsi sebagai media komunikasi.

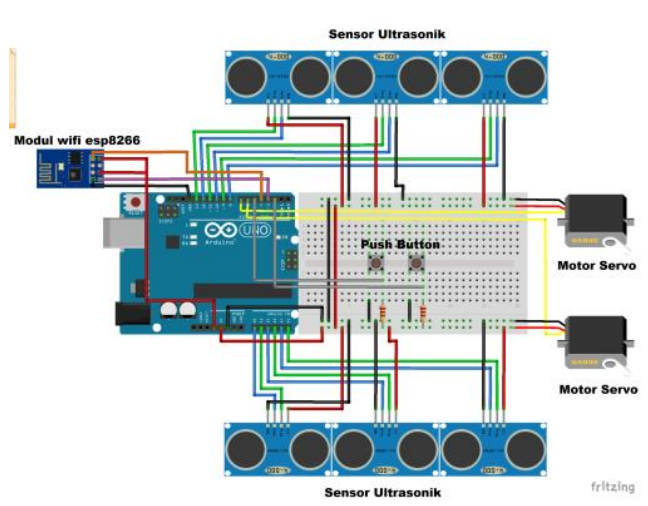

Gambar 3.4 Skema rangkaian alat

Alokasi konfigurasi dan penggunaan pin pada rangkaian alat ditunjukan pada Tabel 3.1 sebagai berikut:
Tabel 3.1 Tabel Konfigurasi Pin Rangkaian Alat

\begin{tabular}{|c|c|}
\hline \multirow{2}{*}{ Arduino } & $\begin{array}{c}\text { Perangkat Lain } \\
\text { Modul wifi } \\
\text { ESP8266 }\end{array}$ \\
\hline Ground & Ground \\
\hline$+3.3 \mathrm{~V}$ & VCC \\
\hline D4 & RX \\
\hline D3 & TX \\
\hline & 6 Sensor Ultrasonik \\
\hline $5 \mathrm{~V}$ & VCC \\
\hline Echo \\
\hline A0,A2,A4,D8,D10,D12 & Trig \\
\hline A1,A3,A5,D9,D11,D13 & Ground \\
\hline Ground & 2 Servo \\
\hline & Ground \\
\hline Ground & VCC \\
\hline $5 \mathrm{~V}$ & Out \\
\hline 6,7 & Button \\
\hline & VCC \\
\hline $5 \mathrm{~V}$ & Ground \\
\hline Ground & Input \\
\hline 2,5 & \\
\hline
\end{tabular}

\subsection{Struktur Menu}

Website monitoring parkir bertingkat akan di bangun menggunakan Bahasa pemrograman PHP serta menggunakan database MySQL. Struktur menu website yang akan penulis susun seperti gambar dibawah ini.

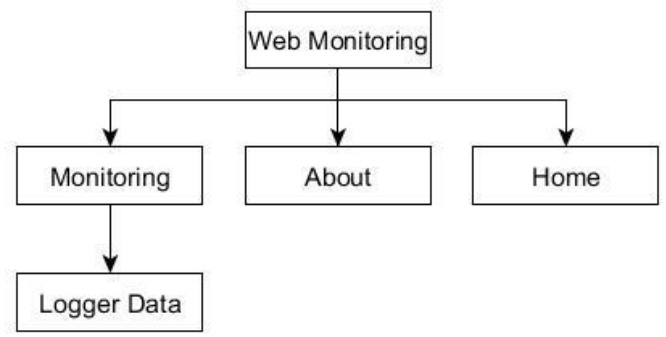

Gambar 3.4 Struktur Menu website

Keterangan :

Menu Home : Digunakan untuk menampilkan halaman utama dan juga keadaan parkir reltime beserta dapat menampilkan cctv.

Menu Monitoring: Digunakan untuk menampilkan informasi yaitu data realtime menampilkan logger.

Menu about :Digunakan untuk memberikan informasi informasi mengenai website.

\section{HASIL DAN PEMBAHASAN}

Website Monitoring parkir bertingkat terdiri dari beberapa halaman masing-masing halaman menampilkan informasi sebagai berikut 


\subsection{Implementasi Menu Monitoring}

Halaman utama seperti pada Gambar 4.1 digunakan untuk menampilkan hasil jumlah kendaraan secara realtime yang berada pada lantai tertentu dan juga beserta jumlah slot kosong yang tersedia dan juga menu untuk memantau cctv tiap lantai.

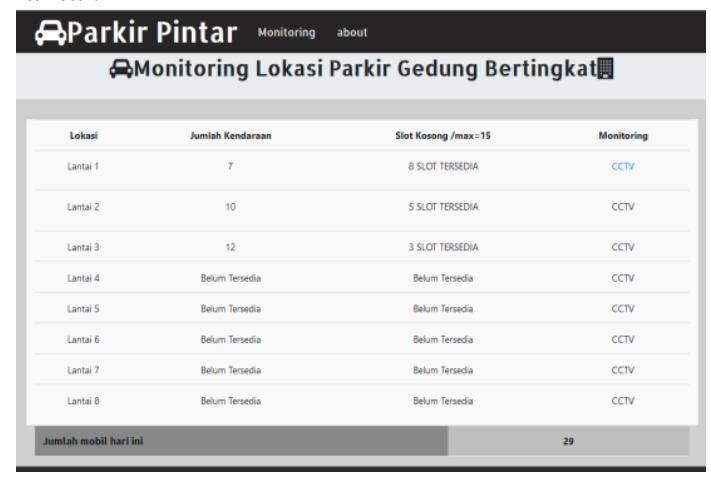

Gambar 4.1 Halaman utama

\subsection{Implementasi Halaman CCTV}

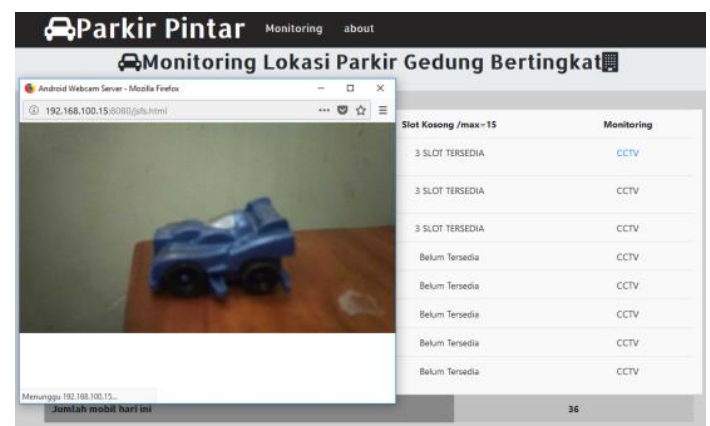

Gambar 4.2 Halaman cctv

Halaman cctv merupakan halaman yang digunakan untuk memantau kendaraan melalui ip kamera.

\subsection{Implementasi Halaman Logger}

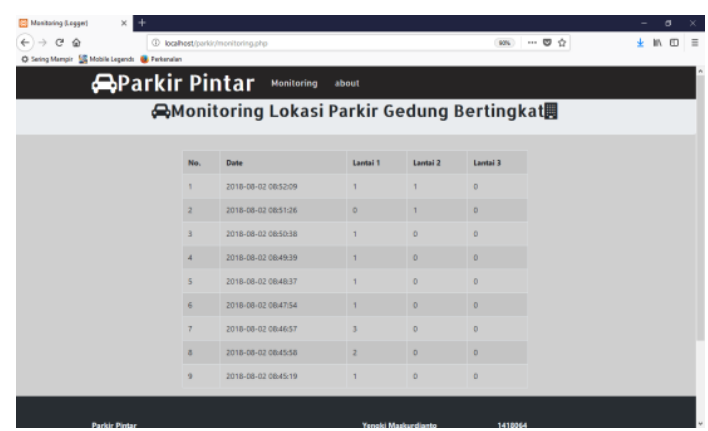

Gambar 4.3 Halaman logger

Halaman logger merupakan hasil halaman logger yang sudah dibuat, menampilkan informasi data yang datanya diambil dari database yang dapat membantu pengelola dalam memonitoring area parkir pada gedung bertingkat.

\subsection{Implementasi Halaman About}

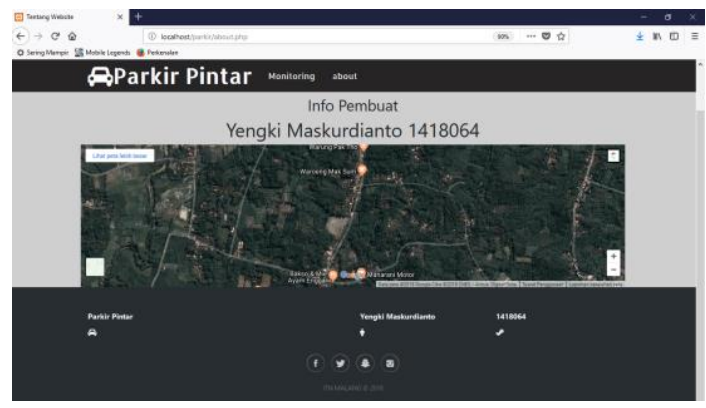

Gambar 4.4 Halaman About

Halaman about berfungsi untuk menampilkan tentang pembuat.

\subsection{Implementasi Prototipe}

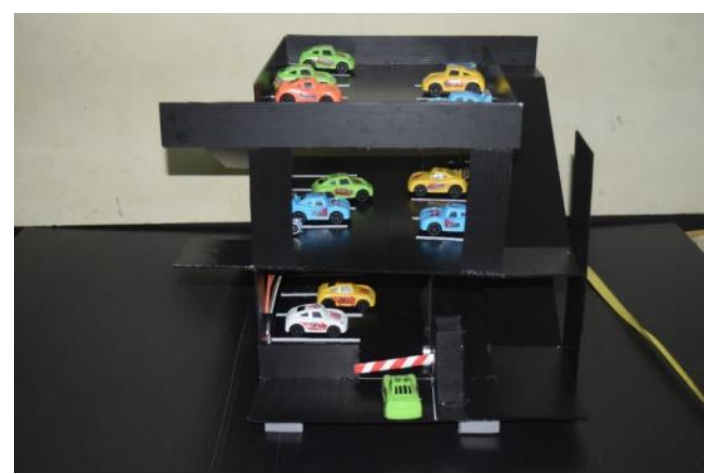

Gambar 4.5 Implementasi Prototipe

Merupakan tampilan gambar prototipe yang sudah didesain untuk percobaan rancang bangun monitoring parkir. Pada prototipe terdapat beberama modul diantaranya pada lantai satu terdapat dua sensor ultrasonik dan dua motor servo sebagai penggerak palang, pada lantai dua terdapat dua sensor ultrasonik, dan pada lantai tiga terdapat dua sensor ultrasonik. Terdapat dua buah motor servo pada lantai pertama, yang berfungsi sebagai motor penggerak pembuka dan penutup palang pintu masuk dan keluar area parkir. Semua modul dihubungkan ke mikrokontroler Arduino uno dengan menggunakan kabel jumper .

\subsection{Pengujian Compability Website Terhadap Web Browser}

Pengujian compability web terhadap web browser bertujuan untuk mengetahui apakah haaman web yang dibuat dapat menampilkan keseluruhan dapa sesuai perancangan dengan beberapa web browser yang sering digunakan oleh user pada umumnya. Hasil uji coba compability web terhadap web browser ditunjukan pada tabel 4.1 berikut 
Tabel 4.1 Pengujian Compability website.

\begin{tabular}{|c|l|r|r|r|}
\hline \multirow{2}{*}{ No } & Aspek pengujian & \multicolumn{3}{|c|}{ Web Browser } \\
\cline { 3 - 5 } 1 & $\begin{array}{l}\text { Mozilla } \\
\text { Firefox }\end{array}$ & $\begin{array}{l}\text { Google } \\
\text { Chrome }\end{array}$ & $\begin{array}{c}\text { Opera } \\
\text { Versi }\end{array}$ \\
\hline & $\begin{array}{l}\text { Menampilkan } \\
\text { halaman } \\
\text { keseluruhan }\end{array}$ & $\checkmark$ & $\checkmark$ & $\checkmark$ \\
\hline 2 & $\begin{array}{l}\text { Menampilkan } \\
\text { informasi slot } \\
\text { parkir }\end{array}$ & $\checkmark$ & $\checkmark$ & $\checkmark$ \\
\hline 3 & $\begin{array}{l}\text { Menampilkan } \\
\text { popup cctv }\end{array}$ & $\checkmark$ & $\checkmark$ & $\checkmark$ \\
\hline 4 & Responsive web & $\checkmark$ & $\checkmark$ & $\checkmark$ \\
\hline
\end{tabular}

\subsection{Pengujian jarak Sensor Ultrasonik}

Pengujian sensor ultrasonik dilakukan dengan cara mengukur jarak benda dengan menggunakan ultrasonik dan selanjutnya diukur menggunakan penggaris dengan jarak benda yang sama sebanyak 5 jarak. Hasil pengujian jarak Ultrasonik dan penggaris dapat dilihat pada tabel 4.2 berikut

Tabel 4.2 Hasil Pengujian Sensor Ultrasonik

\begin{tabular}{|c|c|c|c|c|}
\hline No & $\begin{array}{c}\text { Data } \\
\text { penggaris }\end{array}$ & $\begin{array}{c}\text { Data } \\
\text { Sensor } \\
\text { Srf-04 }\end{array}$ & $\begin{array}{c}\text { Presentase } \\
\text { Error }\end{array}$ & $\begin{array}{c}\text { Rata- } \\
\text { rata \% } \\
\text { error }\end{array}$ \\
\hline 1 & $5 \mathrm{~cm}$ & $5 \mathrm{~cm}$ & $0 \%$ & \multirow{10}{*}{$1,53 \%$} \\
\hline 2 & $9 \mathrm{~cm}$ & $9 \mathrm{~cm}$ & $0 \%$ & \\
\hline 3 & $10 \mathrm{~cm}$ & $10 \mathrm{~cm}$ & $0 \%$ & \\
\hline 4 & $12 \mathrm{~cm}$ & $12 \mathrm{~cm}$ & $0 \%$ & \\
\hline 5 & $15 \mathrm{~cm}$ & $14 \mathrm{~cm}$ & $6,7 \%$ & \\
\hline 6 & $17 \mathrm{~cm}$ & $17 \mathrm{~cm}$ & $0 \%$ & \\
\hline 7 & $20 \mathrm{~cm}$ & $21 \mathrm{~cm}$ & $5 \%$ & \\
\hline 8 & $22 \mathrm{~cm}$ & $22 \mathrm{~cm}$ & $0 \%$ & \\
\hline 9 & $25 \mathrm{~cm}$ & $26 \mathrm{~cm}$ & $4 \%$ & \\
\hline 10 & $28 \mathrm{~cm}$ & $29 \mathrm{~cm}$ & $3,6 \%$ & \\
\hline
\end{tabular}

\subsection{Pengujian Modul Wifi}

Dari prosedur diatas dilakukan pengujian dengan melakukan pengiriman data dari Arduino uno ke web monitoring melalui koneksi Wireless Module ESP8266. Untuk melakukan pengujian ini akan diambil sampel pengiriman data sebanyak 5 kali untuk mengetahui respon yang terima saat melakukan pengiriman data, dapat dilihat pada tabel 4.3.

Tabel 4.3. Hasil pengujian modul wifi ESP8266

\begin{tabular}{|c|c|c|c|c|}
\hline No & $\begin{array}{c}\text { Waktu } \\
\text { Pengiriman }\end{array}$ & $\begin{array}{c}\text { Waktu } \\
\text { Penerimaan }\end{array}$ & $\begin{array}{c}\text { Waktu } \\
\text { delay }\end{array}$ & Ket \\
\hline 1 & $21: 29: 35$ & $21: 29: 40$ & 5 detik & OK \\
\hline 2 & $21: 30: 00$ & $21: 31: 05$ & 5 detik & OK \\
\hline 3 & $21: 32: 00$ & $21: 32: 05$ & 5 detik & OK \\
\hline 4 & $21: 40: 00$ & $21: 40: 05$ & 5 detik & OK \\
\hline 5 & $22: 55: 35$ & $22: 55: 40$ & 5 detik & OK \\
\hline
\end{tabular}

\section{KESIMPULAN DAN SARAN}

\subsection{Kesimpulan}

Dengan adanya penelitian ini, maka didapatkan beberapa kesimpulan yaitu:

1. Sistem yang dibuat merupakan system monitoring dan kontroling parkir bertingkat otomatis.

2. Dapat memonitoring dan mengontrol parkir pada gedung bertingkat.

3. Sistem dapat membantu mempermudah dalam mencari slot parkir yang tersedia.

4. Sistem dapat dimonitoring dimanapun dan kapanpun selama masih terdapat koneksi internet.

5. Alat ini mampu jumlah slot parkir yang digunakan, juga slot yang masih tersedia, dan juga dapat memantau lewat tampilan cetv.

6. Presentase error sensor ultrasonic didapatkan data tertinggi $6,7 \%$ dan terendah $0.00 \%$ dengan rata-rata $1,53 \%$.

7. Pada tahap pengujian kompabilitas website menggunakan 3 browser yaitu Mozilla Firefox 61.0.1, opera, Google Chrome 67.0 dan Microsoft Edge dengan prosentase kompabilitas $100 \%$ berjalan sesuai perancangan

\subsection{Saran}

Rancang bangun sistem monitoring parkir bertingkat ini masih memiliki kekurangan sehiingga dapat dikembangkan agar menjadi lebih baik lagi, untuk pengembangan lebih lanjut terdapat beberapa sayan :

1. Ditambahkan sensor untuk mengetahui kandungan udara didalam tempat parkir.

2. Penambahan sensor untuk mengetahui lebih spesifik slot parkir yang tersedia.

\section{DAFTAR PUSTAKA}

[1] Irawan, J. D., Prasetyo, S., \& Adi, S. (2016). PENGEMBANGAN KUNCI ELEKTRONIK MENGGUNAKAN RFID DENGAN SISTEM IOT. INDUSTRI INOVATIF JURNAL TEKNIK INDUSTRI, 6(2).

[2] Chandra, Richard Nathaniel. Internet Of Things Dan Embedded System Untuk Indonesia. Fakultas Ilmu Hayati Universitas Surya, Vol.3 No.1, 243-912, Januari 2014.

[3] Junaidi, Apri., 2017. INTERNET OF THINGS, SEJARAH, TEKNOLOGI DAN PENERAPANNYA REVIEW.

[4] Limantara,Arthur Daniel., Purnomo, Yosef Cahyo Setianto., Mudjanarko, Sri Wiwoho. 
2017. PEMODELAN SISTEM

PELACAKAN LOT PARKIR KOSONG BERBASIS SENSOR ULTRASONIC DAN INTERNET OF THINGS (IOT) PADA LAHAN PARKIR DILUAR JALAN .

[5] Junaidi, Apri., 2017. INTERNET OF THINGS, SEJARAH, TEKNOLOGI DAN PENERAPANNYA REVIEW.

[6] Budioko, Totok., 2016. SISTEM MONITORING SUHU JARAK JAUH BERBASIS INTERNET OF THINGS MENGGUNAKAN PROTOKOL MQTT.

[7] Arasada, Bakthiyar., Suprianto, Bambang., 2017. Aplikasi Sensor Ultrasonik Untuk Deteksi Posisi Jarak Pada Ruang Menggunakan Arduino Uno.
[8] Limantara ,Arthur Daniel., Purnomo, Yosef Cahyo Setianto., Mudjanarko, Sri Wiwoho., 2017. PEMODELAN SISTEM PELACAKAN LOT PARKIR KOSONG BERBASIS SENSOR ULTRASONIC DAN INTERNET OF THINGS (IOT) PADA LAHAN PARKIR DILUAR JALAN

[9] Yulianto, Novi.,and Bacharuddin, Fahraini., 2016. Perancangan Sistem Informasi Parkir dengan WiFi Berbasis Arduino

[10] Martani, Ahmad., Achmad, Andani., Dewiani., 2013. Prototype Sistem Kontrol Untuk Implementasi Parkir Otomatis Kendaraan Roda Empat 